\title{
The inclusion of pupils perceived as experiencing Social and Emotional Difficulties (SEBD): affordances and constraints
}

\author{
Mowat, Joan, Gaynor ${ }^{1}$ \\ Educational and Professional Studies, University of Strathclyde, Glasgow, Scotland
}

\begin{abstract}
This paper takes as its principal theme barriers to the inclusion of pupils perceived as experiencing social and emotional behavioural difficulties (SEBD) and how these might be overcome. It draws upon an evaluative case study of an initiative, devised by the author, to support pupils - the Support Group Initiative (SGI) - which was conducted over a five year period in a Scottish Secondary School situated in an area of multiple deprivation (SENSP, 2003). The central focus of the discussion is the range of variables which impacted upon pupil outcomes, illustrating the ways in which these variables acted as affordances or constraints in the pursuit of inclusive practice.

The paper takes as its starting point the contested nature of inclusion and introduces, briefly, the Scottish policy context as it pertains to inclusion before exploring the nature of the problem - the barriers to the inclusion of and the difficulties presented by the inclusion of pupils perceived as having SEBD, as discussed within the literature. The findings of the study are discussed in relation to central themes - the ethos of the Support Group; the process of re-signification (Cooper, 1993) through which pupils are enabled to effect improvement; the classroom context; and wider variables relating to school policy, practice, ethos and the management of change. The paper concludes by exploring what inclusion has meant to the pupils involved within the intervention, summarising the affordances and constraints to its realisation, before reflecting upon the significance of the study.
\end{abstract}

\section{Key Words}

social inclusion; Social and Emotional Behavioural Difficulties; social constructivist theory

\section{Introduction}

\footnotetext{
${ }^{1}$ Email: joan.mowat@strath.ac.uk
} 
Inclusion is an elusive and much contested concept, particularly as it pertains to young people perceived as having social and emotional behavioural difficulties (SEBD). This paper argues that inclusion is highly complex and that conflicting imperatives may need to be balanced with each other if schools are to become truly inclusive in their practice. The above will be illustrated by drawing upon an evaluative case study of an initiative the Support Group Initiative (SGI) - which was designed and implemented by the author to support pupils perceived by their Pastoral Care Teachers as having SEBD. The study, carried out over a five year period, was conducted in a Scottish Secondary School situated in an area of multiple deprivation (SENSP, 2003).

\section{A focus upon inclusion \\ The slippery concept of inclusion}

Inclusion means different things to different people. Indeed, it is the lack of concensus as to its meaning which the review of the Salamanca statement -'Salamanca - Ten Years On' (EENET, 2004) - identifies as having hindered progress in its realisation. Smith and Barr (2008), along with a range of other commentators, draw attention to the lack of shared understanding of inclusion, either in terms of its meaning or what it sets out to do. To complicate matters further, the terms 'inclusion' and 'social inclusion' are often used synonymously within the literature. Ainscow, Booth and Dyson (2006) observe that the latter term is often used in relation to vulnerable groups where access to schooling may be under threat - such as gypsy travellers - and, more specifically, pupils with SEBD who are at risk of exclusion from school.

\section{The evolving concept of inclusion: the Scottish policy context}

Inclusion is also elusive in the sense that it is an evolving concept. Within the Scottish policy context, conceptions of inclusion can be traced through a range of policy documents, illustrating the movement from a focus upon integration to inclusion (Pirrie, Head and Brna, 2006) and embracing a range of meanings. Some of these meanings are expressed in relation to the desired outcomes for young people (SOEID, 1998); some are 
expressed in relation to the rights of the child (for example, the 'Standard in Scotland's Schools Etc. Act 2000' (SEED, 2000: Section 6) establishes a presumption of mainstreaming and aims to remove structural and attitudinal barriers to children's participation in mainstream schools); yet others are expressed in relation to the characteristics of an inclusive school (HMIE, 2002).

The 'Additional Support for Learning Act 2004' (SEED, 2004a) brings together under one umbrella of 'Additional Support Needs' (ASN), Special Educational Needs (SEN) and the disparate range of legislation and policies to support vulnerable groups, recognising that support needs may be transient in nature, and embracing a much broader conception of 'needs' than had previously been the case, placing a greater emphasis upon partnership working between all parties.

Whilst all of these aspirations may differ in emphasis and in the ways in which they are expressed, there are commonalities relating to the need to focus holistically upon the needs, potential, abilities and talents of each young person; the ability of young people to take their place in society as effective citizens and to feel included and valued within that society; and to remove barriers to learning.

\section{The barriers to inclusion and the problems presented by inclusion as they pertain to pupils perceived as having SEBD}

Those who advocate inclusion do so on the basis of the benefits to be accrued not only to those to 'be included' but to the school community as a whole on the basis that it should promote tolerance, understanding and respect for diversity which may extend even beyond the confines of the school to the community at large. They also argue that accommodations to practice and the gradual assimilation of values in keeping with the promotion of inclusion enhance teacher professionalism, encouraging teachers to become more reflective in their practice, to the benefit of all children's learning and personal and social development. Whilst recognising that there are barriers to be overcome in the pursuit of inclusive practice, they advocate inclusion not only as an ideology but as a practical way forward for schools (Ainscow, Booth and Dyson, 2006), in keeping with 
national policy, enshrined, within the Scottish context, in the National Priorities (SEED, 2000b) and a 'Curriculum for Excellence' (SEED, 2004b).

The literature suggests that, in principle, teachers support such a vision of inclusion and forward the above views in support of it: on occasion, exemplifying it through their own practice (Horne and Timmons, 2007). However, even before consideration is given specifically to the inclusion of pupils perceived as experiencing SEBD, reservations are expressed in terms of the practical feasibility of inclusion; its funding (Audit Scotland/HMIE, 2003); the demands upon the classroom teacher and effects upon the time which teachers are able to devote to other pupils (Horne and Timmons, 2007); the quality of support for pupils (and, in particular, the role of classroom assistants within this process (OFSTED, 2006)); the degree of knowledge, understanding and expertise of classroom teachers (relating to issues pertaining to initial teacher education (ITE) and continuous professional development (CPD)) (Pirrie, Head and Brna, 2006); the demands and difficulties associated with inter-/multi-agency working (Lloyd, Stead and Kendrick, 2001); and issues pertaining to the decision making process and the role which parents, pupils and professionals play within this process (Pirrie, Head and Brna, 2006). If one then adds into this maelstrom the disruption to learning which can ensue when pupils experiencing SEBD and who are having difficulty in coping with the demands of school life (particularly within the Secondary sector) are 'included', it is evident that the inclusion of such pupils is likely to be perceived as highly problematic. These problems are compounded in areas of multiple deprivation where a higher proportion of the school population may be defined as having SEBD (as reflected in National Exclusion Statistics in which there is a strong positive correlation between the Scottish Index of Multiple Deprivation, free school meal registration and exclusion openings (SENSP, 2007) $)^{1}$ ). A range of studies (Cullingford, 1999; Kendall et al., 2001; Kinder, Wakefield and Wilkin, 1996) identify the experiences of schooling of pupils who had been excluded from school as frustrating and unfulfilling, failing to meet their needs: 'They felt they had become trapped in a negative cycle where problems with schoolwork cause them to feel disengaged and frustrated, which in turn led to bad behaviour.' (The Prince's Trust, 2002, $\mathrm{p} 48)$. 
Pirrie, Head and Brna (2006) identify that teachers have a sense of inclusion being imposed upon them, leading them to distance themselves from the needs of the children whom they perceive to be the source of the problem. Adams (2005) observes, 'Teachers mainly perceive the policy (the presumption of mainstreaming) as being mainly about including every child in the mainstream school, irrespective of behaviour and irrespective of their effect on other pupils.' (Adams, 2005:48). OFSTED, 2006, note that pupils with BESD (behavioural, emotional and social difficulties) were the least likely (amongst the potential SEN population) to receive additional support or to receive it too late, a finding corroborated by Audit Scotland/HMIE (2003), who noted that they were the least likely to have a Record of Need, and Pirrie, Head and Brna (2006), who observe the phenomenon of 'too little - too late', highlighting the need for early intervention and preventative action.

MacLeod and Munn (2004) make the case that SEBD should be considered as a 'different kind of special educational need'. According to the authors, the individual, medical or deficit (IMD) model of disability (Giddens, 2006) has two components - a normative judgement in which the individual is considered relative to others and a judgement about the underlying nature of the difficulty. They argue that, in the case of SEBD, whilst the normative aspect is of value, the judgement pertaining to the nature of the difficulty is less valid on the basis that the process of identifying a child as having SEBD is largely subjective and because it may not be a constant, influenced by factors other than those inherent within the child (Ibid, p170-172). Wilkin et al. (2006) note the difficulty experienced by teachers in distinguishing between 'naughtiness' and a pupil's inability to behave appropriately. Such difficulties, and the sensitivities around such, present a major challenge to schools in addressing the problems posed by SEBD. Indeed, some would argue that SEBD is a social construct. Graham (2006) argues that schools themselves create rather than just respond to SEBD through 'the use of psychopathologizing discourses' and practices which lead to the 'recognition of particular children as a particular kind of 'disorderly' (Graham, 2006 in Graham, 2008, p9). In contrast to the positioning of the problem in relation to the individual, Araujo (2005) notes that 'indiscipline is presented as a problem that emerges in the home and that is carried into school' (Ibid, p245). Teachers are portrayed as re-acting to and the victims of 
the problem and the role of schools is perceived as 'amelioration/remediation' of the indiscipline thus minimising the role which they play in producing it and leading to solutions which focus upon the individual rather than upon scrutiny of policy at the institutional level (Ibid, p245-247). The author argues further that the discourse surrounding indiscipline leads to a polarisation in the categorisation of pupils as being either disrupter or disrupted which leads to a focus upon management of the problem rather than a focus upon the support for learning which is offered to other pupils with SEN (Ibid, p247-251), a point endorsed by Head (2005) in his advocacy of "Better Learning - Better Behaviour" rather than the converse, the latter of which is reflected in the Scottish policy document (SEED, 2001).

McCluskey (2005) draws attention also to this polarisation in the categorisation of pupils and notes that the division between the disrupted and disruptive is not as clear as often portrayed - 'pupils ... are both disrupted and disruptive to some extent' (Ibid, p172). Cullingford (1999), likewise, draws attention to the unclear boundaries between 'bully' and 'bullied', 'being abused' and 'abusing', and 'victim of crime' and perpetrator of crime', highlighting the need for a more sophisticated understanding of the issues. This is corroborated within the statistics relating to referrals to the Children's Hearing system in Scotland. Waterhouse et al. (2004) note that of the 482 children whose records were examined, two-thirds were referred on the grounds of child protection and on offence grounds, the evidence being that as children progress through the system they move from being 'at risk' to being perpetrators of crime.

\section{Addressing the problem}

All of the above highlight the complexity and severity of the problem and therefore the difficulties inherent in addressing it, implying that a 'one-size-fits-all' approach is not desirable and that a range of approaches, responsive and flexible, to meet differing needs is required. It is important therefore that the Support Group Initiative is perceived in this light - as one of a range of options available to local authorities and schools.

\section{Why support groups? (a personal account)}


The initial rationale for support groups was almost entirely pragmatic - a response to a problem. As a newly appointed Assistant Head Teacher responsible for the welfare and discipline of S2 (Senior 2) pupils (aged 12 - 13 years), I became aware of the frequency with which the same pupils were referred constantly to me for indiscipline and of the inadequacy of my response to this problem. However, I was also motivated by a desire to make a difference - to give meaning to my professional life.

My initial response to this difficulty was to raise the issue at a meeting of the Senior Management Team (SMT) and to forward a two-pronged approach to addressing it. The first, a whole-school approach towards promoting positive behaviour, focussing upon school policy and staff development; the second, the focus of this specific study, an approach targeted specifically at the needs of those pupils perceived to be at greatest risk of disaffection from school and those who were already demonstrating behaviours associated with such, such as persistent late-coming, truancy, disruptive behaviour and/or failure to come to school prepared adequately for study.

\section{Why this specific approach?}

Through a process of reflection and drawing upon experiential learning and reading, I became aware of the need to impact at a level beyond that of 'strategies' - of the need to help young people to arrive at a deeper understanding of their values, beliefs and motivations and the emotions underlying them, and those of others, such that they would gain insight into their interpersonal relationships, which lie at the heart of SEBD - to develop a 'theory of mind' (Astington, 1994) and empathy, within a context of ethical and moral values. Such an approach requires of the adult mediating the learning process to draw upon social constructivist theories of learning to foster understanding and transfer and to model ethical and moral values through their conduct.

\section{What are Support Groups?}


Support Groups constitute three-to-six S2 (Secondary 2) pupils who meet weekly for around twenty sessions with a Support Group Leader (SGL) (volunteers drawn principally from Pastoral Care and Behaviour Support staff) who leads them through collaborative activities which are designed to promote discussion and self-reflection. Pupils are nominated by their Pastoral Care Teachers and permission is sought of the pupils themselves and their parents before groups are formed. The approach aims to develop further in pupils the personal intelligences (Gardner, 2006) such that they impact upon pupils' capacities to regulate their behaviour with good judgement in a range of contexts, to form and maintain effective interpersonal relationships and for empathy; pupils' self-esteem and confidence; and the development of more positive learning dispositions and attitudes towards school.

The approach draws upon a wide range of theories of learning and, in particular, the work of David Perkins and his colleagues at Project Zero (the Harvard Graduate School of Education) on Teaching for Understanding and Transfer, and Multiple Intelligence Theory (Gardner); Thinking Skills (the 'Activating Children's Thinking Skills' framework (McGuinness), drawing upon the work of Swartz and Parks); Emotional Intelligence (Cobb and Mayer; Mayer and Salovey; Goleman); Theory of Mind (Astington); and Achievement Motivation Theory (Dweck and Elliot; McLean). It brings to bear upon the affective field, social constructivist theories of learning, integrating the cognitive and affective domains.

\section{The study}

The study draws from the paradigms of case study (Bassey, 1999), action research (Somekh, 2006; Mills, 2007) and evaluative study (Watt, 1988). Issues of subjectivity/objectivity and therefore, validity, are particularly acute within the conduct of an Action Research study thus careful attention was devoted to triangulation (Bassey, 1999, Gillham, 2000) in the design and implementation stages of the study: whilst it is largely qualitative, it draws also upon quantitative methods. Whilst this multi-method approach may appear compromised to purists on the basis that one is separating the method from the theoretical framework from which it emanates (its epistemology, 
ontology, understandings of the individual and social world ...), Gillham (2000) makes the case that one of the most important considerations in the design and conduct of a study should be its 'fitness for purpose'; Watt (1998) argues for the appropriateness of the model and style chosen and the rigour of its execution; and Humes (2001) describes the quest for purity in research methods as an illusion - particularly as it applies within the "messy, indeterminate situations", characterised by "uncertainty, uniqueness and value conflict" which characterise the school setting (Ibid, p25). The study synthesises and analyses the accounts of 69 S2 pupils and those most closely affected by the study parents, Support Group Leaders, Pastoral Care Teachers, class teachers and senior management.

Six in-depth case studies (Cohort 2002) were conducted with the assistance of Stuart Hall (Scottish Council of Research in Education (SCRE)) drawing from the 34 pupils who formed cohort 2001-2002. A randomised sample was rejected on the basis that the population from which it would be selected was relatively small, and it was considered that a stratified multi-phased sampling method, taking account of different criteria at each stage, would be more likely to produce a more representative sample. Selection was according to:

1 the degree of initial concern (mild/-mid/severe) about the pupil (derived from examination of discipline records) cross-referenced to the initial response of the pupil to the intervention (measured at the mid-intervention point) (deterioration/no change/improvement $)^{2}$

2 the Support group which the pupil participated in

3 gender of the pupil

4 wider criteria (for example, the pupil's involvement in other interventions)

honing down to six categories, one pupil from each of which was selected by Stuart Hall, who was entirely independent of the study.

Benchmark measures were established for the Support Group (SG) population, comparing their performance on a range of indicators - attendance, discipline measures, attainment in National Tests in English (reading and writing) and pupil attitudes 
(measured by means of a Semantic Differential Scale devised by myself) - to wider populations - national, local authority and other pupils within the year group. Pupil progress was measured from the commencement of Secondary Schooling (S1) until the end of S3, examining not only statistical data but drawing also upon accounts of pupil progress by the Depute Head (S3) and upon retrospective interviews conducted with a sample of SG pupils (one third of SG pupils) based upon a stratified random sample.

At the immediate end of intervention in S2, all SG pupils were interviewed by their SG Leaders (who had received training in interview methods), and class teachers, SGLs and parents completed a questionnaire. Whilst being aware that note-taking does not provide such an authentic and full account of the interviews, I decided to adopt this method on the basis that it may be perceived by participants as less formal, and therefore less constraining, and it places fewer demands in relation to subsequent transcription (Drever, 1995) (a factor which required consideration because of the professional demands upon myself). In order to ensure greater reliability, individual accounts were verified either by paraphrasing back the individual accounts during the interview itself and/or by providing a written transcript. All research tools were piloted with my own SG pupils. The normal ethical procedures were adhered to, being sensitive to issues relating to potential roleconflict and power relations, given my role within the school.

Qualitative data were analysed by means of content analysis. Silverman (2001) expresses concern about its use within qualitative studies but I would argue that his conceptualisation of it is narrow - he conceives of only one means of carrying it out - by prior identification of categories against which the data are classified, the analyist being constrained by his/her tacit understandings. Gillham (2000) makes a case for grounded theory, characterised by inductive theorising, and that is the method which was adopted within this specific study, the categories arising from the data itself, adopting a flexible approach. Care was taken to avoid anecdotalism (Gillham, 2000) and, whilst Popper's theory of falsification (1959) (as cited in Silverman, 2001) can more readily be applied to quantitative approaches, if account is taken of the truth claims made, it can also be applied to interpretivist approaches, actively seeking the full range of evidence, both positive and negative, and reflecting it in the balance of the report. Quantitative data were 
analysed via both parametric (stem and leaf analysis, study of distribution of sample (S) means) and non-parametric (chi-squared tests) methods.

One of the principal considerations in relation to case study is the extent to which the findings are generalisable beyond the specific case. Perhaps the answer to this dilemma lies in the nature of the claims made for the study, which, in turn, rest upon the conceptualisation of the study and its fundamental purpose. If one is setting out to establish universal truths, as in positivist approaches, then case study is clearly inadequate. However, if one conceptualises the purpose of the study as being to illuminate the issues for others, such that they can understand their own specific circumstances more fully, then case study is eminently suited to this purpose. Case study has the potential to enable the researcher to 'uncover the multi-faceted complexity of human behaviour in groups and organizations' (Somekh, 2006, p24) in a way in which positivist approaches cannot. At the least, this specific study should serve to further understanding of the complexities surrounding the inclusion of pupils with SEBD and the facilitators and impediments to such, and to illuminate the issues for others working within the field - theorists, practitioners and the policy community.

\section{Research aims and questions}

The study had three main purposes:

1 to establish if theories derived from the cognitive field (c.c. 'What are Support Groups?') can be applied to the affective field and to ascertain the effect of such upon pupil outcomes

2 to establish the worth of the Support Group Initiative (SGI)

3 to seek to understand SEBD in all of its complexity and to ascertain the significance of the study for imperatives within Scottish Education, such as inclusion and social justice.

The first two research questions are concerned with establishing whether the intervention had impacted upon the development of the personal intelligences (RQ1) and, 
if so, the impact which this had upon the range of desired outcomes previously described (c.c. 'What are Support Groups?') (RQ2)

The third research question is related to point 2 above - it is concerned with establishing the strengths and weaknesses of the approach, with identifying variables which impact upon pupil outcome and whether the effect upon pupils (whether positive or negative) lasts over time. RQ4 is related to point 3 above and seeks to establish the contribution which the study makes to knowledge transformation and its implications for policy and practice.

\section{Findings and discussion}

The principal focus of this discussion is RQ3, and, in particular, the variables which affect pupil outcome, discussed under key themes, as it is these which help to illuminate the affordances and constraints in relation to the quest for inclusive schooling (related to RQ4). This will lead into a concluding section synthesising the themes from the paper and discussing the implications of the study for inclusive practice.

\section{The Ethos of the Support Group}

The most important cluster of variables centred around the ethos of the Support Group and the role which the SGL played in creating the climate of the group and in fostering understanding. Establishing trusting, respectful relationships lies at the heart of Support Group work and the initiative provides a forum in which pupils can talk about issues of importance to them, in a safe secure environment, knowing that they will be listened to. Post-intervention, $92 \%$ of pupils identified with the positive effects of 'being listened to' and over half with a sense of 'being cared about': 'I used to worry that you would pass on what I was saying to my Mum and others but you didn't. You listened to my version of things when I was in trouble and that made me listen more to what you had to say.'

(Martin) ${ }^{3}$

Parents valued the opportunity which the Support Groups offered for their children to 'open up' and they attributed their children's growing confidence to this: 'At school he 
finds it hard to speak up in front of others - it built up his confidence to speak up.' (Stewart's Aunt)

\section{The process of re-signification}

Cooper (1993) describes the process of re-signification as the means by which people can develop more positive self-images of themselves, re-framing the situations in which they find themselves. How might this be achieved?

A key component is a 'significant other' - an adult who has faith in the capacity of the young person to change and who conveys this through their words and actions to the child. Further, the adult needs to have the tenacity to hold onto the young person (corroborated in Lloyd, Stead and Kendrick, 2001) through what can be quite a difficult journey. Through participation in the learning community (Nuthall, 2002 in Brophy (ed.); Wenger, McDermott and Snyder, 2002) which is the Support Group, the young person gradually assimilates the values and the ways of being which are associated with it those of mutual respect, confidentiality, being listened to and listening respectfully to others and valuing the contribution which individuals can make. The young person needs to recognise the need to change, have the motivation to do so, to take responsibility for their own behaviour and have a sense of self-efficacy and agency.

The above are reflected in many stakeholder accounts.

I've got to thank teachers for helping me, for telling me, "You can do this". (James)

I used to deny it all and I never used to really think about it but now I know if I've done something wrong. (Fraser)

There was a very dramatic change. In group discussion, I remember him saying, "I know sir I get it wrong but I'm trying hard to get it right". And he did. (Ross's SGL)

The positive role which SGLs had played in fostering improvement is commented upon by many parents: 'Good relationship with SGL has helped.' (Mark's mother) 
The SGL also plays an important role in addressing the low aspirations which many disaffected young people hold - a sense of being trapped within communities as was expressed by one boy in group discussion, 'But I'm from the ........' (Josh) and reflected in this comment from his SGL: 'He seems to be dominated by what is expected of him due to the community in which he lives. His behaviour is somewhat dominated by what he regards as 'street cred'. He would like to escape this.' (Mrs McFadden)

\section{The classroom context}

One of the key goals of Support Groups is that they should enable young people to reengage with education and foster dispositions which will dispose them towards learning, reflected in RQ2. Kinder, Kendall and Howarth (2000), drawing from previous studies, identify that it is a breakdown in three central relationships within Secondary schools teachers, peers and the curriculum - which lies at the heart of disaffection from school. The learning which takes place within Support Groups is important but what is essential is the capacity of the pupil to use that knowledge, flexibly and appropriately in the wider context of the school, in their relationships and in their lives at home and within the community. This is the focus of RQ2, reflecting one of the aims of the SGI. It is the essence of 'Teaching for Understanding' as propounded by Perkins (Perkins, 1998 in Wiske (ed.)) and for transfer (Perkins and Salomon, 1998, 1989).

If pupils are to succeed in their endeavours, it is dependent therefore not only upon the context of the Support Group itself (and the degree to which the SGL teaches for understanding and transfer) but upon factors which are external to the groups themselves, such as school policies, practice and ethos, relationships within classrooms (particularly those with teachers) and the nature of the curriculum and how it is delivered (pedagogy).

\section{A focus upon relationships}

It has already been established that teachers (and, in particular, SGLs) can be a force for good. However, it is not evident from parental and pupil accounts that the positive relationships which had formed between pupil and SGL extended beyond to other 
teaching staff - 'Although he is now getting on very well with his Guidance teacher (SGL), he doesn't say much about his other teachers' (Dean's Mum) - although it was certainly the case for some pupils: 'Has realised that everyone wasn't against him and that, if he tries hard, the teachers will try with him.' (Stewart's Aunt)

In the pre-assessment self-assessments (which were carried out by $46 \mathrm{SG}$ pupils (Cohorts $2001 \&$ 2002) and a comparator group of 110 S2 pupils who had not been referred to Senior Management for indiscipline), highly significant statistical differentials (established by means of chi-squared tests) emerged between the two groups in relation to a range of statements relating to interpersonal relationships. Those which distinguished SG pupils most from their peers were (Table 1):

\begin{tabular}{|l|c|c|}
\hline & $\mathrm{x}^{2}$ value & $\mathrm{p}$ \\
\hline I get on well with my teachers & 46 & $<.001$ \\
I try to show respect towards my teachers & 34 & $<.001$ \\
I am usually friendly towards other pupils & 34 & $<.001$ \\
Most of my teachers don't like me & 29 & $<.001$ \\
Most of my teachers don't try to be fair & 26 & $<.001$ \\
\hline
\end{tabular}

Table 1: Statements, relating to interpersonal relationships, which distinguished SG pupils most from a comparator group on a self-assessment semantic differential scale

These differences could be quite stark: for example only one of the 46 SG pupils claimed to get on well with their teachers in comparison to 67 of the comparator group (61\%). It is also evident that it is relationships with teachers (rather than with peers) which were perceived by the SG pupils to be most problematic.

Post-intervention, some class teachers drew attention to more positive relationships forming between themselves and SG pupils: 'We now have a good relationship. He talks and asks questions sometimes - especially before and after class.' (Mark's teacher) This is verified in pupil accounts, whereby $50 \%$ of SG pupils identified more positively with 'I try to show respect towards my teachers', but 'Most of my teachers like me' and 'Most of my teachers care about me' were most resistant to change. More positive 
perceptions of peer relationships - 'I get on well with my friends' $(60 \%)$ had the highest rating of all.

A few parents observed that class teachers were not always supportive: 'While we agree he is immature in his attitude towards school work, he feels some teachers are not helpful towards what he is trying to achieve.' (Jamie's Dad) It is evident that SG pupils were struggling to cast off established reputations even when pupil outcomes were quite remarkable. Thomas, for example, had amassed 30 referrals for serious indiscipline and 23 days of exclusion from school within the single term prior to intervention. Postintervention, his referrals dropped by $75 \%{ }^{4}$ and exclusions reduced to 4 days (in the final term), yet his class teachers did not comment upon any improvements in his behaviour. These feelings of injustice, of being 'scapegoated' are reflected within the literature (Kinder, Wakefield and Wilkin, 1996; Hamill and Boyd, 2000; Hamill, Boyd and Grieve, 2002; Kendall et al., 2001; Lloyd, Stead and Kendrick, 2001; Munn, Johnstone and Sharp, 1998; Munn, Lloyd and Cullen, 2000; Munn and Lloyd, 2005). Hamill, Boyd and Grieve (2002) report that 'Many staff believe that the right to be treated in a caring way is forfeited by some young people as a consequence of their behaviour', and, accordingly, believe that these young people have lost their right to be treated with respect. This extends further to a belief that these young people should not be in mainstream settings 'One of the big problems in the mainstream classes .. is persuading the teachers that these children should be there.' (Pirrie, Head and Brna, 2006, reporting on the views of a Headteacher)

It is evident in pupil accounts, however, that the majority of pupils were gaining in understanding of the role of the classroom teacher, were more able to understand the perspective of the classroom teacher and were developing in empathy and that this had alleviated some of the frustration and anger felt by SG pupils:

I'm more aware of the demands of the teacher in the classroom. Teachers are different and have different attitudes. I'm more able to see teachers as individuals. I'm less angry than I used to be at teachers and school in general. I can talk to some teachers now. (Liam) 


\section{A focus upon learning}

It is readily apparent in examining statistics relating to attainment in National Tests in reading and writing ${ }^{5}$ that the attainment of SG pupils, prior to intervention, was statistically significantly below that of all comparator groups ${ }^{6}$ (their peers within the school, local authority and nationally). Further, these differences continued to widen over the period of intervention. These statistics indicate that SG pupils (when considered as a whole) would have had great difficulty in accessing the Secondary curriculum.

Yet, in examining the provision of learning support for SG pupils, the proportion of pupils in receipt of such support was low both prior to and during intervention (only four SG pupils participated within the paired-reading scheme). It is hardly surprising therefore that some SG pupils, SGLs and parents drew attention to the frustrations which this situation engendered, manifesting itself in anger and disruption, and SGLs articulated the need for a differentiated curriculum which meets the individual needs of the learner.

I'm aware of becoming annoyed and frustrated - its related to the learning difficulties I have. I need more time than the teacher has to give. I've become aware that the teacher is trying to meet lots of needs within the class. I'm more patient now - I take it less personally. (Liam)

This account, from a pupil within my own group, offers a very sad indictment of the Scottish Education system. Hamill (2008) draws from a range of studies to note the correlation between learning difficulties and disruptive behaviour and the lack of focus upon meeting the learning needs of such pupils (resonating with Head's observations to which reference has already been made).

However, another respect in which SG pupils were not being enabled to fulfil their potential lies in the low expectations held by some of their teachers and, in Alastair's case, other professionals with whom they came into contact. Alastair was described by the Child Psychologist as performing 'satisfactorally', yet he was performing in standardised tests at three years below his chronological age. 
In the pupil self-assessments, differentials of high statistical significance (established by means of chi-squared tests) emerged between the SG population and the comparator group on learning/school related indicators (Table 2).

Table 2: Statements, relating to learning related factors, which distinguished SG pupils most from a comparator group on a self-assessment semantic differential scale

\begin{tabular}{|l|c|c|}
\hline & $\mathrm{x}^{2}$ value & $\mathrm{p}$ \\
\hline I don't consider myself to be a good learner & 33 & $<.001$ \\
I don't like being at school & 32 & $<.001$ \\
I don't think of myself as being quite intelligent & 16 & $<.001$ \\
I don't ask for help when I am stuck & 13 & $<.001$ \\
I can't work at a problem until I get it right & 8 & $<.01$ \\
\hline
\end{tabular}

Post-intervention, around $30-35 \%$ of SG pupils felt more positively in relation to these criteria (for example, they identified more positively with being a good learner). The criterion which was most resistant to change was that of perceptions of intelligence. This is of significance if account is taken of the work of Dweck (1999) who identifies perceptions of intelligence (whether as being amenable to change) and a sense of self efficacy as underlying achievement motivation.

It is evident, however, that some pupils were beginning to develop more positive dispositions towards learning as indicated by a range of stakeholders, exemplified in this comment by a class teacher: 'A willing worker - gets to work quickly, following instructions and doesn't put herself into conflict situations. A marked and welcome change.' (Speaking of Lisa).

Class teacher accounts were generally very variable, indicating the highly context specific, and sometimes erratic, nature of SG pupils' responses and, indeed, some pupils demonstrated a deterioration.

Bringing these two themes together, it is evident that the quality of relationships, both between pupils and teachers and between peers is of the essence as are the need for an appropriate, differentiated curriculum which meets the needs of learners; the early 
identification of learning difficulties; the provision of appropriate, carefully channelled, additional support for learners; and high, yet realistic expectations of pupil performance. It is clear that the SG can impact upon pupils' interpersonal relationships and upon their dispositions towards learning and it may be the case that the development of such dispositions may potentially, over time, impact upon learning outcomes (although the latter has not been established within the study).

\section{Towards inclusive practice: 'Before he was looking in from outside. Now he feels he's a member of our little society'}

To some, the practices described within this article would be considered as exclusionary (in that the approach is based upon extraction from class for specialist support) and predicated upon a deficit model of the child. This section argues that what may first appear to be exclusionary can, in reality, promote inclusion. What is the evidence in support of this argument?

Whilst within the case studies it has been established that parents and pupils had some initial trepidation about participation within the SGI and concerns about possible stigmatisation, these were not realised. There were no reports of pupils being stigmatised or bullied in response to participation although one parent expressed concern about her son 'mixing with those other kids' and one pupil felt ashamed at having been the only member of his family to have been singled out for support. The evidence is to the contrary. Pupils freely asked to join groups and many parents requested places for their children. Indeed, participation within SGs had been a positive experience for the majority of young people, $84 \%$ of whom considered that it had either exceeded or met their expectations. During the period of the study, all pupils (with the exception of those no longer attending the school and one pupil permanently excluded) completed the intervention.

Further, positive effects were still in evidence for the vast majority of pupils who participated within the retrospective interview up to two years after intervention with pupils clearly articulating what they had gained from the experience: "It taught me respect for people around me. Making a clown of myself - people laughing at me - not 
with me. Others are trying to learn - they don't need me disrupting them.' (James) However, these positive outcomes were not achieved for all pupils and it is evident that participation was not easy for a few young people: 'I hate people bringing up what I've done - I don't like being confronted with it.' (John)

Whilst some parents, SGLs and pupils reported upon the development of more positive attitudes towards school and dispositions towards learning -'His attitude towards teachers is so different. He now wants to go to school.' (Stewart's Aunt) - this is not reflected in higher attendance rates. In keeping with the national trend, attendance declined from S1S3 for both the SG population and other pupils in the year group ('other') but the proportion of absences accounted for by unauthorised absence (inclusive of exclusion openings) by the SG population fell from $53 \%$ in $\mathrm{S} 1$ to $36 \%$ in $\mathrm{S} 3$.

Likewise, whilst the differential in exclusion openings between the SG population and 'other' remained of high statistical significance beyond intervention $\left(x^{2}=95, p<.001\right)$, the chi-squared value reduced by a factor of 24 , each population demonstrating opposing trends of statistical significance ${ }^{7}$ (SG population - improvement; 'other' - deterioration). These opposing trends were also in evidence for referrals to senior management for indiscipline and continued into S3. The SGI had served to stem deterioration for the vast majority of pupils and, for some, a reduction in measures for indiscipline was achieved and this was most marked for those pupils initially categorised as being of 'severe concern'.

However, perhaps of greater importance, is the ethos of the school. SGLs reported that participation within the initiative had encouraged them to perceive the young people in their charge in a new light. It had been a positive experience for both pupils and SGLs: 'It was very satisfying personally - I was able to get closer to the students.' (Mr Liddell) However, a few SGLs expressed their concerns about the capacity of mainstream schools to meet the needs of some of the most disturbed young people: 'He needs some expert help - more than we can provide.' (Mr Hannah). The majority of class teachers considered that the SGI had helped to promote inclusion within the school: 'I dread to think what would have happened to him without intervention.' (class teacher) This view is shared by SGLs and senior management. Parents also considered that the SGI had helped to keep their children within the system, in a few cases, preventing permanent 
exclusion. It had helped to forge more positive relationships between home and school and some parents expressed their desire to continue working with the school beyond intervention. However, it is less clear that it had impacted upon the values, beliefs and practices of class teachers which highlights the importance of a whole school approach and the need to tackle the problem on all fronts.

The challenges, however, had been great. Initial response to the intervention had been, at best, lukewarm and, at worst, hostile. It had been difficult to persuade teachers that pupils with SEBD were deserving of support and it was only through strenuous efforts and determination that the approach gradually gained acceptance within the school.

\section{Management of the change process}

Management of change is highly complex and it is important to take account of the state of readiness of the school to move forward (Fullan, 2003). Whilst some might argue that an inclusive ethos is best promoted through focussing principally upon the practice, values and beliefs of staff, this does not take account of the fact that children only have one chance at their education and that change takes time. Educators are faced with the decision about what they can do in the 'here and now' to ensure that the learning experience for the pupils in front of them is 'the best that it can be'. Whilst it is necessary to have a vision and to share that vision with others, sometimes the choice comes down to not ideally where one should start but where one can start. Sometimes, it is only through small, incremental steps that change comes about, leading by example and establishing communities of practice through which values and beliefs become internalised and people are enabled to confront their assumptions and re-appraise their attitudes. Over time, it became accepted in the school that pupils with SEBD were deserving of support and senior managers noted a willingness of staff to lead groups, which speaks for itself.

\section{Synthesising the themes of the paper}

One of the key findings of this study is that inclusion has been felt and experienced in a wide range of different ways, individual to each pupil. For some pupils, it can be equated 
with 'keeping them within the system', preventing further deterioration, and therefore with a policy of mainstreaming. For others, it has meant having a greater sense of affinity with the school community, being accepted, being listened to and, in turn, responding by being more respectful and empathetic in their relationships with others. For many, it has led to greater insight into their interpersonal relationships and insight into the values, beliefs and motivations of others. For others still, it has meant being able to participate more readily within the life of the school - more able to exercise judgement and selfcontrol enabling them to develop a greater sense of self-respect, impacting upon their self-esteem and confidence. And, in some cases, it has led to the forming of more positive dispositions towards learning, a greater understanding of the purpose of school and more positive attitudes forming towards it. Further, for some pupils, these positive effects had extended beyond the context of the school to their lives beyond it $^{8}$. These outcomes have been experienced to varying degrees and are highly context related.

There are many facilitators of inclusion which have been identified through this study. Key amongst them have been the role of the Support Group Leader in teaching for understanding and transfer and in creating the ambience of the group, and the understanding, skills, values and beliefs which he/she brings to this task; the quality of leadership and management and the supports put in place in place to enable this to take place (the design of the programme itself, the programme of staff training, mentoring and regular meetings between Support Group Leaders); the support of the Senior Management Team, of class teachers and the adoption of a whole-school approach; the support of parents and the extended family; and the commitment which individual pupils bring to the endeavour (and the range of factors discussed in relation to the process of resignification).

Impediments to inclusion, however, are also varied and diverse, relating to a wide range of variables. Amongst them, the failure to recognise pupils experiencing SEBD as being in need or deserving of additional support; the low expectations held of pupils regarded as having SEBD which are reflected in the low aspirations held by the young people themselves and the sense of being 'trapped within communities'; the failure to identify and address learning needs adequately; the frustrations experienced by young people who cannot shake off poor reputations despite all of their efforts - an issue relating not only to 
the attitudes of teaching staff themselves but the quality of support for staff (including ITE and CPD), the tone set by senior management, the culture of the school and the policy context within which the school operates; and the failure to support adequately families within communities such that parents are enabled to fulfil their role as parents and to recognise that 'schools cannot go it alone'. The sheer size and complexity of schools, particularly Secondary schools, makes the management of change problematic and this, in itself, presents as a barrier to inclusion.

This paper has synthesised a range of themes and has argued that inclusive practice (whilst difficult to define) can be achieved in a variety of ways and it is important to be open to these various ways. The SGI offers a way forward for schools and should be considered as one of a range of interventions which has the potential to impact positively upon pupil outcomes if implemented effectively. Further, social constructivist approaches can be applied effectively to the affective field, and, in particular, to working with young people perceived as having SEBD. The study clearly resonates with national policies such as 'Better Behaviour - Better Learning', 'A Curriculum for Excellence', 'Happy, safe and achieving their potential', 'More choices, more chances' and, within the wider UK context, ' Every Child Matters', addressing national imperatives such as inclusion, social justice and raising achievement.

\section{Notes}

1 of the 42,900 exclusion openings (per 0.5 days) in Scotland in session 2005/06, $39.8 \%$ were accounted for by pupils registered for free school meals (c.c. table 10), the highest rates of exclusion openings corresponding to children living in the most deprived wards (c.c. chart 5) on the Scottish Index of Multiple Deprivation

2 such categorisations arrived at through examining the lie of the dispersions

3 all names are pseudonyms

4 after controlling for absence for reasons other than suspension from school

5 those relating to mathematics were not examined for reasons of reliability

6 for example, the differentials in performance (as measured in chi-squared tests) between the SG population and their peers within the year group at level D in reading and writing are $\mathrm{x}^{2}=21$ and $\mathrm{x}^{2}=20$ respectively, both $\mathrm{p}<.001$

7 for example, reduction in exclusion openings for the SG population $\left(x^{2}=10, p<.001\right)$ in contrast to the increase for 'other' $\left(\mathrm{x}^{2}=5, \mathrm{p}<.05\right)$

8 these categorisations are not mutually exclusive.

\section{References}


Adams, F. 2005. Discipline in Scottish Schools: A Survey of Teachers' Views, Edinburgh: GTCS Ainscow, M., T. Booth, and A. Dyson. 2006. Improving Schools, Developing Inclusion, London: Routledge

Araujo, M. 2005. Disruptive or disrupted? A qualitative study on the construction of indiscipline. International Journal of Inclusive Education 9, no. 3, 241-268

Astington, J.W. 1994. The Child's Discovery of the Mind. London: Fontana Press

Audit Scotland/HMIE. 2003. Moving to Mainstream: The Inclusion of pupils with special educational needs in mainstream schools. Edinburgh: HMSO

Bassey, M. 1999. Case Study in Educational Settings, Oxford: Oxford University Press

Cooper, P. 1993. Effective Schools for Disaffected Students: Integration and Segregation, London: Routledge

Cullingford, C. 1999. The Causes of Exclusion: Home, School and the Development of Young Criminals, London: Kogan Page Limited

Drever, E. 1995. Using Semi-Structured Interviews in Small-Scale Research: a teacher's guide. Edinburgh: SCRE

Dweck, C.S. 1999. Self Theories: Their Role in Motivation, Personality and Development, Philadelphia: Psychology Press

Enabling Education Network. 2004. EENET Special Edition: Salamanca - Ten Years On, Newsletter: Issue 8

Fullan, M. 2003. Change Forces with a Vengeance, New York: Routledge Falmer

Giddens, A. 2006. Sociology, 5th ed. Cambridge: Polity Press, Blackwell Publications

Gillham, B. 2000a. Case Study Research Methods. London: Continuum

Graham, L. J. 2008. From ABCs to ADHD: the role of schooling in the construction of behaviour disorder and production of disorderly objects. International Journal of Inclusive Education 12, no. $1,7-33$

Hamill, P. 2008. Challenging Behaviour - Understanding and Responding, Paisley: Hodder Gibson

Hamill, P. and B. Boyd. 2000. Striving for Inclusion: The Development of Integrated Support Systems for Pupils with SEBD in Secondary Schools in YYY, Glasgow: Strathclyde University Hamill, P., B. Boyd, and A. Grieve. 2002. Inclusion: Principles into Practice: Development of an Integrated Support System for Young People (SEBD) in XXX, Glasgow: Strathclyde University

Head, G. 2005. Better Learning - Better Behaviour. SER, 37, no. 2, 94 - 103

HMIE. 2002. Count us in - Achieving Inclusion in Scottish Schools, Edinburgh: HMSO

Horne, P. E. and V. Timmons. 2007. Making it work: teachers' perspectives on inclusion. International Journal of Inclusive Education. 1-14, iFirst Article 
Humes, W. 2001. Examining the role and status of educational research in Scotland. Edinburgh: SERA, 25-26

Kendall, S., M. A. Cullen, R. White, and K. Kinder. 2001. The Delivery of the Curriculum to Disengaged Young People in Scotland, England: NfER

Kinder, K., S. Kendall, and A. Howarth. 2000. Disaffection Talks (Paper presented at the NFER Council of Members Meeting, 4.10.02 in London)

Kinder, K., A. Wakefield, and A. Wilkin. 1996. Talking Back: pupil views on disaffection, England: NFER

Lloyd, G., J. Stead, and A. Kendrick. 2001. Hanging on in there: A study of inter-agency work to prevent school exclusions in three local authorities, London: National Children's Bureau and the Joseph Rowntree Foundation

McCluskey, G. 2005. What does discipline mean in Secondary schools now? SERJ 37, no. 2, 163 174

MacLeod, G. and P. Munn. 2004. Social, Emotional and Behavioural Difficulties: A Different Kind of Special Educational Need? SERJ 36, no. 2, 169-176

Mills, G. E. 2007. Action Research: a Guide for Teacher Researchers, $3^{\text {rd }}$ ed. Ohio: Pearson: Merrill Prentice Hall

Munn, P., M. Johnstone. and S. Sharp. 1998. Is indiscipline getting worse? Scottish teachers' Perceptions of Indiscipline in 1990 and 1996. SERJ 30. no. 2, 157-172

Munn, P. and G. Lloyd. 2005. Exclusion and excluded pupils. BERJ 31, no. 2, April, 2005

Munn, P., G. Lloyd and M. A. Cullen. 2000. Alternatives to Exclusion from School, London: Chapman Publications

Nuthall, G. 2002. Social Constructivist Teaching and the Shaping of Students' Knowledge and Thinking. In Social Constructivist Teaching: Affordances and Constraints, 43-79. ed. J. Brophy. U.S.A.: JAI.

OFSTED. 2006. Inclusion: does it matter where pupils are taught? Executive summary. London: OFSTED

Perkins, D. 1998. What is Understanding? In Teaching for Understanding, 39-58. ed. Wiske, M.S. USA: Jossey-Bass.

Perkins, D. and G. Salomon, 1988. Teaching for Transfer. Educational Leadership 51, no. 5, 2232

. 1989. Are Cognitive Skills Context Bound? Educational Researcher, Jan - Feb, 1989, 16-25

Pirrie, A., G. Head and P. Brna.. 2006. Mainstreaming Pupils with Special Educational Needs: An Evaluation, Edinburgh: HMSO

Prince's Trust (The). 2002. The Way it is: young people on race, school exclusion and leaving care. London: The Prince's Trust 
SEED. 2000. Standards in Scotland's Schools etc. Act 2000. Edinburgh: HMSO

SEED. 2001. Better Behaviour - Better Learning. Edinburgh: HMSO

SEED. 2004a. Education (Additional Support for Learning) (Scotland) Act. Edinburgh: HMSO

SEED. 2004b. A Curriculum for Excellence. Edinburgh: HMSO

Scottish Executive National Statistics Publication. 2003. Scottish Indices of Deprivation 2003, retrieved 06.07.04 from http://www.scotland.gov.uk/library5/social/siod-00.asp

Scottish Executive National Statistics Publication. 2007. Exclusions from schools, 2005/06, retrieved 20.10.08 from http://www.scotland.gov.uk/Publications/2007/01

SOEID. 1998. Social Inclusion: Opening the Door to a better Scotland. Edinburgh: HMSO

Silverman, D. 2001. Interpreting Qualitative Data: Methods for Analysing Talk, Text and Interaction. $2^{\text {nd }}$ ed. London: SAGE publications

Smith, R. and S. Barr. 2008. Towards educational inclusion in a contested society: from critical analysis to creative action. International Journal of Inclusive Education 12, no. 4, 401-422

Somekh, B. 2006. Action Research: A methodology for change and development. Berkshire: OUP

Waterhouse, L., J. McGhee and N. Loucks, 2004. Disentangling Offenders and Non-Offenders in the Scottish Children's Hearing: A Clear Divide? Howard Journal of Criminal Justice 43., no. 2, 164-179 (abstract)

Watt, J. 1988. Evaluation in Action: a case study of an under-fives centre in Scotland, 7-29. Israel: Bernard van Leer Foundation.

Wenger, E., R. McDermott and W. Snyder. 2002. Cultivating Communities of Practice, Boston, MA: Harvard University Business School Press

Wilkin, A., H. Moor, J. Murfield, F. Johnson and K. Kinder. 2006. Behaviour in Scottish Schools: Insight Paper 34. Edinburgh: HMSO 